\title{
Comparison of Intra-Articular Bupivacaine and Neostigmine with Bupivacaine and Fentanyl for Post-Operative Analgesia in Arthroscopic Knee Surgeries
}

\author{
Prachi Singh ${ }^{1}$, Sandeep Kumar Yadav ${ }^{2}$, Sumit Kumar ${ }^{3}$, Manoj Tripathi ${ }^{3}$, Deepak Malviya ${ }^{4}$ \\ ${ }^{1}$ Senior Resident, Department of Anaesthesia, RMLIMS, Lucknow, U.P, India, ²Junior Resident, Department Of Anaesthesia, RMLIMS, Lucknow, U.P, India, \\ ${ }^{3}$ Assistant Professor, Department Of Anaesthesia, RMLIMS, Lucknow, U.P, India, ${ }^{4}$ Professor And Head, Department Of Anaesthesia, RMLIMS, Lucknow U.P, India.
}

\section{Abstract}

Background: The post-operative pain in knee arthroscopy procedures can be attributed to irritation of free nerve endings of synovial tissue, anterior fat pad, and joint capsule during surgical excision and resection1. In the recent years, new interest has focused on the cholinergic system that modulates pain perception and transmission. The present study is designed to compare the efficacy of intra- articular Bupivacaine and Neostigmine with Bupivacaine and Fentanyl for pain relief following arthroscopic surgeries. Subjects and Methods: Prospective, Interventional, Randomised study was conducted over 90 patients scheduled for elective arthroscopic knee surgery, who were randomly allocated into three equal groups of 30 patients each. Group I-Bupivacaine with Neostigmine, Group II-Bupivacaine with Fentanyl and Group III-Bupivacaine alone. The study drug combinations were administered Intra-articularly at the conclusion of surgery. Hemodynamic variables and Pain were observed immediately after completion of surgery (Baseline) and thereafter at fixed intervals. The duration of effective analgesia was measured from the "baseline" until the first use of rescue analgesic. The number of rescue analgesics given in 24 hours were also recorded. The statistical analysis was done using SPSS (Statistical Package for Social Sciences) Version 15.0 statistical Analysis Software. Results: Requirement for first analgesia was significantly earlier in Group III (146.00 \pm 71.66 minutes) as compared to Group II (236.00 \pm 111.34 minutes) and Group I (648.00 \pm 228.55 minutes). Majority of patients of Group I (90.0\%) required rescue analgesia only once while in was twice in Group II $(90.00 \%)$ and thrice in Group III (86.67\%). Conclusion: Intra-articular administration of Neostigmine in combination with Bupivacaine provided a better post-operative analgesic effect with a lower incidence of side effects and lesser requirement of rescue analgesia.

Keywords: Neostigmine, Fentanyl, Bupivacaine, Arthroscopy.

Corresponding Author: Dr. Sumit Kumar, Assistant Professor, Department Of Anaesthesia, RMLIMS, Lucknow, U.P, India. Email: drsumit1995@gmail.com

Received: April 2020

Accepted: April 2020

\section{Introduction}

The post-operative pain in knee arthroscopy procedures can be attributed to irritation of free nerve endings of synovial tissue, anterior fat pad, and joint capsule during surgical excision and resection. ${ }^{[1]}$ Intra-articular injection of different drugs after arthroscopy can reduce the pain significantly and decrease the need for analgesic. ${ }^{[2]}$ In the recent years, new interest has focused on the cholinergic system that modulates pain perception and transmission. The acetyl-choline esterase inhibitor Neostigmine, has demonstrated a dose- dependant analgesia following spinal or epidural administration. ${ }^{[3,4]}$ Moreover, in animal studies, Neostigmine when given alone through intra-articular route, has shown to bring about histo pathological changes in articular cartilage and synovium of knee joint. ${ }^{[5]}$ The present study is designed to compare the efficacy of intra- articular Bupivacaine and Neostigmine with Bupivacaine and Fentanyl for pain relief following arthroscopic surgeries.

\section{Aims and Objective}

To compare the efficacy of combination of Bupivacaine and Neostigmine with Bupivacaine and Fentanyl administered intra-articularly for postoperative pain relief in patients undergoing arthroscopic knee surgeries in terms of duration of analgesia and hemodynamic changes. In addition, to note the side effects, if any, of the study drugs.

\section{Subjects and Methods}

Prospective, Interventional, Randomised study was conducted in Department of Anaesthesiology, Era's Lucknow Medical College \& Hospital, Lucknow over 18 months. After obtaining approval from the Institutional Ethical Committee, 90 patients between age group 18-50 years with ASA GRADE I \& II, scheduled for elective arthroscopic knee surgery were randomly allocated into three 
equal groups of 30 patients each. Group I- $20 \mathrm{ml}$ of $0.25 \%$ Bupivacaine $+1 \mathrm{ml}(500 \mu \mathrm{g})$ of Neostigmine. Group II- $20 \mathrm{ml}$ of $0.25 \%$ Bupivacaine $+1 \mathrm{ml}(50 \mu \mathrm{g})$ of Fentanyl. Group III$20 \mathrm{ml}$ of $0.25 \%$ Bupivacaine $+1 \mathrm{ml}$ of Normal saline. The surgery was carried out under sub-arachnoid block. At the conclusion of surgery, the study drug combinations were administered by the operating surgeon into the knee joint space via $18 \mathrm{G}$ needle. Hemodynamic variables and Pain were observed immediately after completion of surgery (Baseline) and thereafter at 1 hour, 2 hour, 4 hours, 8 hours, 12 hours, 16 hours, 20 hours and 24 hours. The duration of effective analgesia was measured from the "baseline" until the first use of rescue analgesic. The number of rescue analgesics given in 24 hours were also recorded. Pain was assessed using 10-point Visual Analogue Scale (VAS). Time to First complain of pain with VAS score $>4$ in the postoperative period was recorded and Injection Diclofenac $75 \mathrm{mg}$ i.m was given as rescue analgesic. Adverse effects like nausea, vomiting, hypotension, bradycardia, respiratory distress, urinary retention and pruritus was documented and managed accordingly.

\section{Statistical Tool Employed}

The statistical analysis was done using SPSS (Statistical Package for Social Sciences) Version 15.0 statistical Analysis Software. The values were represented in Number
$(\%)$ and Mean \pm SD . Analysis of Variance (ANOVA) test was used to compare the within group and between group variances amongst the study groups i.e. the three different sealers. Analysis of variance of these three sealers at a particular time interval revealed the differences amongst them. ANOVA provided " $F$ " ratio, where a higher " $F$ " value depicted a higher inter-group difference. Paired "t" test used to compare the change in a parameter at two different time intervals. Kruskall Wallis H Test, Mann- Whitney U test and the Wilcoxon signed rank statistic test were also used.

\section{Results}

Difference in age, gender and body weight of patients of above three groups was not found to be statistically significant. Most common diagnosis among study population was ACL tear $(n=38 ; 42.22 \%)$ followed by Pain knee $(n=33$; 36.67) while less common diagnosis was PCL tear $(n=14$; $15.56 \%)$ and Arthritis knee $(\mathrm{n}=3 ; 3.33 \%)$. Difference in clinical diagnosis of patients of above three groups was not found to be statistically significant $(p=0.214)$. Pulse rate, systolic BP and diastolic BP of patients of above three groups were found to be comparable at all the periods of observation after baseline $(\mathrm{p}>0.05)$.

Table 1: Intergroup Comparison of Pain (VAS) at different time intervals

\begin{tabular}{|c|c|c|c|c|c|c|c|c|c|c|c|}
\hline & \multicolumn{3}{|c|}{ Group I $(n=30)$} & \multicolumn{3}{|c|}{ Group II $(n=30)$} & \multicolumn{3}{|c|}{ Group III $(n=30)$} & \multicolumn{2}{|c|}{ Kruskal-Wallis H test } \\
\hline & Md & Mn & SD & Md & Mn & SD & Md & Mn & SD & H & $\mathbf{P}$ \\
\hline Baseline & 2.00 & 2.00 & 0.00 & 2.00 & 2.00 & 0.00 & 2.00 & 2.00 & 0.00 & 0.000 & 1.000 \\
\hline $1 \mathrm{~h}$ & 2.00 & 2.00 & 0.00 & 2.00 & 2.00 & 0.00 & 2.00 & 2.47 & 0.86 & 15.012 & 0.001 \\
\hline $2 \mathrm{~h}$ & 2.00 & 2.00 & 0.00 & 2.00 & 2.60 & 0.93 & 3.00 & 3.00 & 1.02 & 19.216 & $<0.001$ \\
\hline $4 \mathrm{~h}$ & 2.00 & 2.20 & 0.61 & 4.00 & 3.13 & 1.01 & 2.00 & 2.60 & 0.93 & 14.892 & 0.001 \\
\hline $8 \mathrm{~h}$ & 2.00 & 2.60 & 0.93 & 2.00 & 2.27 & 0.69 & 2.00 & 2.40 & 0.81 & 2.507 & 0.287 \\
\hline $12 \mathrm{~h}$ & 2.00 & 2.87 & 1.01 & 2.00 & 2.13 & 0.51 & 4.00 & 3.07 & 1.01 & 15.863 & $<0.001$ \\
\hline $16 \mathrm{~h}$ & 2.00 & 2.27 & 0.69 & 2.00 & 2.47 & 0.86 & 2.00 & 2.40 & 0.81 & 1.004 & 0.605 \\
\hline $20 \mathrm{~h}$ & 2.00 & 2.27 & 0.69 & 2.00 & 2.93 & 1.01 & 2.00 & 3.00 & 1.02 & 10.504 & 0.005 \\
\hline $24 \mathrm{~h}$ & 2.00 & 2.00 & 0.00 & 2.00 & 2.27 & 0.69 & 2.00 & 2.80 & 1.00 & 16.838 & $<0.001$ \\
\hline
\end{tabular}

Table 2: Intergroup Comparison of Time for first analgesia requirement (minutes) of Study Population

\begin{tabular}{|l|l|l|l|l|l|l|}
\hline Group & No. & Min. & Max. & Median & Mean & S.D. \\
\hline Group I & 30 & 240 & 1200 & 720 & 648.00 & 228.55 \\
\hline Group II & 30 & 120 & 480 & 240 & 236.00 & 111.34 \\
\hline Group III & 30 & 60 & 240 & 120 & 146.00 & 71.66 \\
\hline Total & 90 & 60 & 1200 & 240 & 343.33 & 266.52 \\
\hline
\end{tabular}

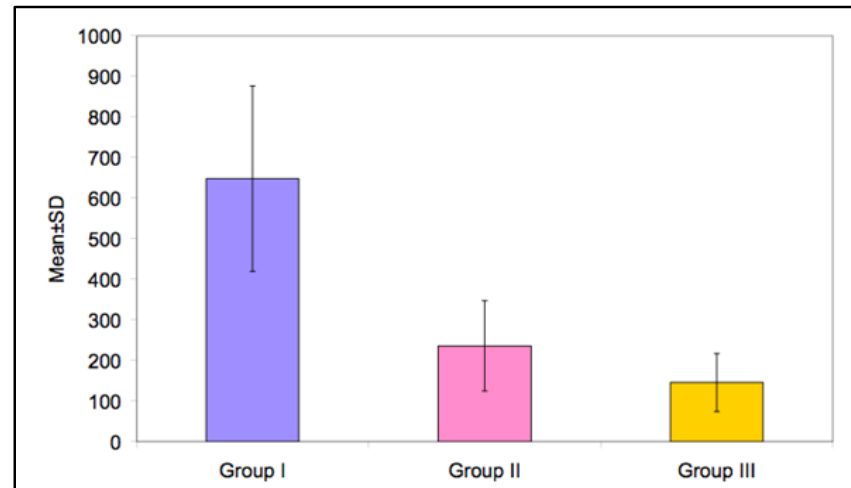

Figure 1: Intergroup comparison of time for first analgesia requirement (minutes) of study population
Table 3: Intergroup Comparison of frequency of Rescue analgesia of Study Population

\begin{tabular}{|c|c|c|c|c|c|c|c|}
\hline \multirow{2}{*}{$\begin{array}{l}\text { No. of } \\
\text { times } \\
\text { rescue } \\
\text { analgesia } \\
\text { required }\end{array}$} & \multirow[t]{2}{*}{$\begin{array}{l}\text { Total } \\
(\mathrm{N}=90)\end{array}$} & \multicolumn{2}{|c|}{$\begin{array}{l}\text { Group I } \\
(n=30)\end{array}$} & \multicolumn{2}{|c|}{$\begin{array}{l}\text { Group II } \\
(n=30)\end{array}$} & \multicolumn{2}{|c|}{$\begin{array}{l}\text { Group III } \\
(n=30)\end{array}$} \\
\hline & & No. & $\%$ & No. & $\%$ & No. & $\%$ \\
\hline 1 & 30 & 27 & 90.00 & 3 & 10.00 & 0 & 0.00 \\
\hline 2 & 34 & 3 & 10.00 & 27 & 90.00 & 4 & 13.33 \\
\hline 3 & 26 & 0 & 0.00 & 0 & 0.00 & 26 & 86.67 \\
\hline \multicolumn{8}{|c|}{$\chi^{2}=128.329(\mathrm{df}=4) ; \mathrm{p}<0.001$} \\
\hline \begin{tabular}{|r|}
$100 \%$ \\
$90 \%$ \\
$80 \%$ \\
$70 \%$ \\
$60 \%$ \\
$50 \%$ \\
$40 \%$ \\
$30 \%$ \\
$20 \%$ \\
$10 \%$ \\
$0 \%$ \\
\end{tabular} & roup 1 & $=1 \mathrm{Dc}$ & $\square 2$ Dose & $=3 \mathrm{DC}$ & & & \\
\hline
\end{tabular}

Figure 2: Intergroup comparison of frequency of rescue analgesia of study population 
At baseline, pain score of patients of Group I, Group II and

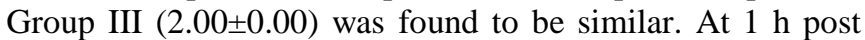
operatively, pain score of patients of Group III $(2.47 \pm 0.86)$ was found to be significantly higher as compared to Group I $(2.00 \pm 0.00)$ and Group II $(2.00 \pm 0.00)$. At $2 \mathrm{~h}$ post operatively, pain score of patients of Group III (3.00 \pm 1.02$)$ and Group II $(2.60 \pm 0.93)$ were found to be significantly higher as compared to Group I $(2.00 \pm 0.00)$. At $4 \mathrm{~h}$ post operatively, pain score of patients of Group II $(3.13 \pm 1.01)$ and Group III $(2.60 \pm 0.93)$ were found to be significantly higher as compared to Group I (2.20 \pm 0.61$)$. [Table 1]

Requirement for first analgesia was significantly earlier in patients of Group III (146.00 \pm 71.66 minutes) as compared to Group II (236.00 \pm 111.34 minutes) and Group I
$(648.00 \pm 228.55$ minutes). Between Group difference Mean \pm SD among Group II \& Group III was not found to be statistically significant. Order of requirement of rescue analgesia was Group III $\approx$ Group II $<$ Group I. [Table 2]

Majority of patients of Group I (90.0\%) required rescue analgesia only once while majority of patients of Group II $(90.00 \%)$ required rescue analgesia two times and majority of patients of Group III $(86.67 \%)$ required rescue analgesia three times during the period of observation. None of the patients of Group I and Group II required rescue analgesia for three times and none of the patients of Group III required rescue analgesia for one time only. Difference in number of times requirement of rescue analgesia among patients of above three groups was found to be statistically significant.

Table 4: Intergroup Comparison of Adverse effects in Study Population

\begin{tabular}{|c|c|c|c|c|c|c|c|c|c|}
\hline \multirow[t]{2}{*}{ Adverse effects } & \multirow[t]{2}{*}{ Total $(\mathrm{N}=90)$} & \multicolumn{2}{|c|}{ Group I $(n=30)$} & \multicolumn{2}{|c|}{ Group II $(n=30)$} & \multicolumn{2}{|c|}{ Group III $(\mathbf{n}=30)$} & \multicolumn{2}{|c|}{ Statistical significance } \\
\hline & & No. & $\%$ & No. & $\%$ & No. & $\%$ & $\chi^{2}$ & $\mathbf{P}$ \\
\hline Vomiting & 13 & 0 & 0.00 & 6 & 20.00 & 7 & 23.33 & 7.732 & 0.021 \\
\hline
\end{tabular}

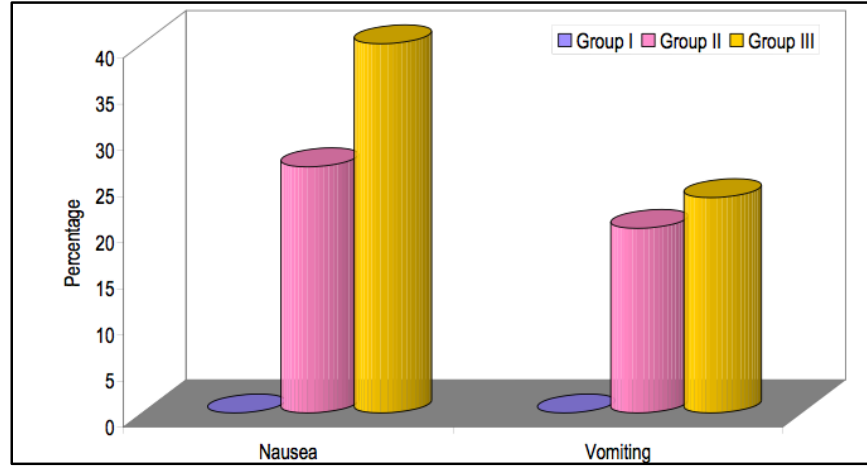

Figure 3: Intergroup comparison of adverse effects in study population

Adverse effects Nausea and vomiting were observed in higher proportion of patients of Group II and Group III as compared to Group I. Difference in prevalence of patients with adverse effect of Nausea among patients of Group I (0.0\%), Group II (26.67\%) and Group III (40.00\%) was found to be statistically significant $(\mathrm{p}<0.001)$. Similarly, prevalence of patients with adverse effect of Vomiting among patients of Group I (0.0\%), Group II (20.00\%) and Group III (23.33\%) was also found to be statistically significant.

\section{Discussion}

Intra-articular injection of different drugs after arthroscopy can reduce the pain significantly and decrease the need for analgesic. ${ }^{[6]}$ Intra articular injection of neostigmine acts by stimulation of peripheral muscarinic receptors, and hence does not accompany the side effects related with use of opioids that act by stimulation of nicotinic receptors and hence is often considered to be relatively safer. ${ }^{[7]}$ It has been shown to be effective when used singly after the arthroscopic knee surgery or when given in combination with Bupivacaine. ${ }^{[7-12]}$ Despite its potential to reduce the opioid related side effects, there are no comparative studies available comparing its efficacy in combination with Bupivacaine to that of Fentanyl (an opioid) in combination with Bupivacaine.

Age of patients ranged from 18 to 50 years with a mean age 32.47 years. Statistically, there was no significant difference among groups with respect to age. An attempt was made not to include elderly patients in the study as the pharmacodynamics of Neostigmine has been shown to be affected by age. ${ }^{[13,14]}$ In different previous studies too, inclusion of elderly has been avoided, probably for this reason7. In their study, Datta and Madhusudanan ${ }^{[9]}$ restricted the age range from 22 to 35 years only. Yang et al. ${ }^{[7]}$ too in their study included patients up to 60 years of age and reported the mean age of patients between 37 to 44 years in different groups.

During the entire course of study, the three study groups did not show a significant difference in hemodynamic parameters like heart rate, systolic blood pressure, diastolic blood pressure. Moreover, no adverse events like hypotension, hypertension, bradycardia, tachycardia and respiratory depression took place, thus showing that both the drug combinations were safe and did not pose any cardiovascular risk. This hemodynamic profile is similar to various studies reviewed by us that have not reported any serious hemodynamic event in Fentanyl or Neostigmine group. ${ }^{[9-12,15-22]}$ Kayacan et al. ${ }^{[8]}$ compared intra- articular Neostigmine to intra-articular Tramadol, Tenoxicam and Bupivacaine and found that compared to Bupivacaine group, Neostigmine had a relatively much stable hemodynamic profile, thus indicating that Neostigmine exercises a better hemodynamic control as compared to Bupivacaine. In the present study, Bupivacaine was used in all the three groups, however, hemodynamic profile of Neostigmine was no different from Bupivacaine alone group thus signifying that Neostigmine did not induce any additional hemodynamic change and thus was safe to be used even when used in combination with Bupivacaine.

In present study, all the cases in three groups had pain score of 2 at baseline. However, at $1 \mathrm{hr}$, both the study groups maintained the mean pain score to 2 whereas in control group the mean VAS score for pain was significantly higher

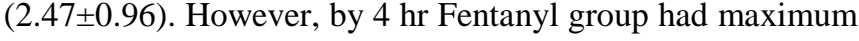
pain scores. At 8 and 12 hours intervals, mean pain scores 
were higher in Neostigmine group as compared to that in Fentanyl group. However, the pain scores must be interpreted in context with the time taken for rescue analgesia. In Neostigmine group, the mean time taken for rescue analgesic was $648 \pm 228.55$ minutes (minimum 240 min, maximum $1200 \mathrm{~min}$ ) whereas in Fentanyl group this duration was $236 \pm 111.34 \mathrm{~min}$ (minimum $120 \mathrm{~min}$, maximum $480 \mathrm{~min}$ ). However, in Bupivacaine alone group this duration was only $146 \pm 71.66$ min (minimum 60 and maximum 240 hours). The median period was $720 \mathrm{~min}, 240 \mathrm{~min}$ and 120 min in Neostigmine, Fentanyl and Bupivacaine groups respectively. This implies that in Bupivacaine group, almost half the patients had received their first rescue analgesic dose within $120 \mathrm{~min}$. Thus after 120 minutes interval, the pain scores in Bupivacaine group were influenced by the rescue analgesic. Similarly, in Fentanyl group, at least half the patients had received rescue analgesic by $240 \mathrm{~min}$. Hence, in Fentanyl group the pain scores were substantially affected at $240 \mathrm{~min}$ and thereafter with the introduction of rescue analgesia. In contrast, in Neostigmine group, none of the patients required analgesia by $240 \mathrm{~min}$ and the proportion of patients requiring analgesia reached to $50 \%$ or above at only 720 minutes. Thus, the pain scores in Neostigmine group remained free from rescue analgesic effect up to 720 minutes.

The findings in present study are similar to the observations made by Yang et al. ${ }^{[7]}$ who observed that $500 \mu \mathrm{g}$ of intraarticular Neostigmine as compared to $2 \mathrm{mg}$ intra-articular Morphine and intra-articular Normal saline was able to not only prolong the rescue analgesic free period but also had significantly lower VAS scores at all time periods up to 24 hr. In their study, mean rescue analgesia free duration was close to $50 \mathrm{~min}$ in Normal saline, close to $200 \mathrm{~min}$ in Morphine and close to $350 \mathrm{~min}$ in Neostigmine group. Relatively higher rescue analgesic free time in present study could be attributable to the additional use of $0.25 \%$ Bupivacaine. In another study, Lee12 showed that even Neostigmine alone provides a comparable response as compared to addition of $0.125 \%$ Bupivacaine, thus showing that Neostigmine is a useful and strong analgesic when administered intra-articularly among patients undergoing arthroscopic knee surgeries.

Datta and Madhusudanan, ${ }^{[9]}$ in their study among patients undergoing arthroscopic knee surgery also reported that as compared to Bupivacaine alone group, Neostigmine in combination with Bupivacaine increased the post- operative rescue analgesic free time by more than twice. In their study, they made comparison of these two modalities with Morphine alone group and found that Morphine alone group had rescue analgesic free time lesser than half, thus showing that opioids alone had even poorer post-operative analgesic effect as compared to Bupivacaine alone group, whereas Neostigmine alone group performed similar to Neostigmine in combination with Bupivacaine. Thus signifying that intraarticular administration of Neostigmine either alone or in combination with Bupivacaine has superior analgesic effect as compared to either Bupivacaine alone, opioids alone or a combination of Bupivacaine \& opioids.

A more objective assessment of rescue analgesic free time was done by Algaol et al. ${ }^{[10]}$ in a study that compared intraarticular $500 \mu \mathrm{g}$ Neostigmine to $2 \mathrm{mg}$ Morphine and $100 \mathrm{mg}$
Bupivacaine and showed the mean rescue analgesia free time in the three groups to be $517.2 \mathrm{~min}, 300.6 \mathrm{~min}$ and $308 \mathrm{~min}$ respectively. Thus, as compared to opioid group, Neostigmine group had 1.72 times longer analgesic free time and as compared to Bupivacaine group it had 1.68 times longer analgesic free time. In present study when used in combination with Bupivacaine, Neostigmine had 4.44 times longer analgesic free time as compared to Bupivacaine alone and 2.75 times longer analgesic free time as compared to opioid + Bupivacaine group. The higher efficacy against Bupivacaine alone group in present study could be attributable to the addition of Bupivacaine with Neostigmine instead of Neostigmine alone as in their study. Kayacan et al. ${ }^{[8]}$ in their study did not find a significant difference in rescue analgesia free time between Neostigmine alone and Bupivacaine groups, however, this may be owing to a higher concentration of Bupivacaine used in their study $(0.5 \%)$ which was twice that used in present study $(0.25 \%)$, against the same dosage of Neostigmine as used in present study $(500 \mu \mathrm{g})$.

Unfortunately, there are no studies available comparing Neostigmine with Fentanyl either alone or in combination with Bupivacaine. Most of the neighbouring evidence comes from the studies that have compared Morphine with Neostigmine and found that Neostigmine outperforms the Morphine. Given the fact that Fentanyl has a lesser analgesic effect as compared to Morphine, Neostigmine out performed Fentanyl too. ${ }^{[9,10]}$

In present study, the number of rescue dosages showed an incremental trend with $90 \%$ of those in Neostigmine group requiring only single dose of rescue analgesic while $90 \%$ of those in Fentanyl group required only two dosages of rescue analgesic but $86.67 \%$ of those in Bupivacaine alone group required 3 rescue dosages of analgesia. This finding indirectly indicates the total amount of rescue analgesia to be almost three times that of Neostigmine in Bupivacaine and almost 2 times higher than that of Neostigmine in Fentanyl group. Similar to results of present study, Algaol et al. ${ }^{[10]}$ in their study showed consumption of rescue analgesic up-to 72 hours to be 2.3 times higher in both Morphine as well as Bupivacaine groups. Mitra et al. ${ }^{[18]}$ in their study made observations up-to $8 \mathrm{hrs}$ and found that number of patients requiring analgesia was 2.4 times Fentanyl combination. Prolongation of analgesic effect up-to 1200 minutes (20 hrs) is in itself an indicator of lesser analgesic requirement in Neostigmine group as compared to Fentanyl and Bupivacaine groups in present study.

On evaluation of side effect profile of present study, we did not find any CNS side effect such as nausea and vomiting in Neostigmine supplemented group. This could be probably due to a nicotinic receptor sparing action of Neostigmine, when given intra articular. However, a high prevalence of patients in Bupivacaine alone group presenting with complaints of nausea and, vomiting in Bupivacaine and Fentanyl group remains an issue. One of the reasons for higher proportion of these side effects in patients could be owing to a higher use of rescue analgesia in these groups.

These outcomes are useful in providing a better patient satisfaction, early mobilization and lesser discomfort to the patients. Incidentally, this is the first study that has compared intra-articular Fentanyl and Bupivacaine combination with 
Neostigmine and Bupivacaine combination in arthroscopic knee surgeries and was found to be in accordance with neighbouring evidence available. However, these findings still need further exploration for different drug-dose combinations and considering the efficacy of Neostigmine alone to be as beneficial in certain studies, further studies are recommended on different drug-dose combinations. Moreover, studies incorporating hospital stay, patient higher in Bupivacaine alone group as compared to Bupivacainesatisfaction and financial implications as outcomes are also recommended to assess the impact of different interventions in more objective terms.

\section{Conclusion}

The findings of present study suggest that Neostigmine in combination with Bupivacaine provided a better postoperative analgesic effect with a lower incidence of side effects and lesser requirement of rescue analgesia. On the basis of observations made in our study in terms of efficacy and adverse effects of the study drug combinations, intraarticular administration of combination of Bupivacaine and Neostigmine can effectively and safely be recommended for post-operative pain relief in patients undergoing arthroscopic knee surgeries. Though the results of the present study are logical and explainable, further substantiation and validation of outcomes of the study is recommended.

\section{References}

1. Weale AE, Ackroyd CE, Mani GV, Winson IG. Day-case or short-stay admission for arthroscopic knee surgery: a randomised controlled trial. Ann R Coll Surg Engl. 1998;80(2):146-9.

2. McGrath B, Elgendy H, Chung F, Kamming D, Curti B, King S. Thirty percent of patients have moderate to severe pain $24 \mathrm{hr}$ after ambulatory surgery: a survey of 5,703 patients. Can J Anaesth. 2004;51(9):886-91.

3. Pavlin DJ, Chen C, Penaloza DA, Buckley FP. A survey of pain and other symptoms that affect the recovery process after discharge from an ambulatory surgery unit. J Clin Anesth. 2004;16(3):200-6.

4. Dye SF, Vaupel GL, Dye CC. Conscious neurosensory mapping of the internal structures of the human knee without intra-articular anesthesia. Am J Sports Med. 1998; 26:773-7.

5. Salwa MS Hayes Emadeideen S, Naser, Adham A, Geidi EI. Effect of intra-articular injection of midazolam and/or Bupivacaine on postoperative analgesia after arthroscopic knee surgery. Egypt J Anesth. $2012 ; 28: 147-51$.
6. Paul S, Bhattacharjee DP, Ghosh S, Dawn S, Chatterjee N. Efficacy of intra-articular dexmedetomidine for postoperative analgesia in arthroscopic knee surgery. Ceylon Med J. 2010;55(4):111-15.

7. Yang LC, Chen LM, Wang CJ, Buerkle H. Postoperative analgesia by intra-articular Neostigmine in patients undergoing knee arthroscopy. Anaesthesiology 1998; 88: 334-9.

8. Kayacan N, Boztuğ N, Arici G, Karsli B, Erman M. The effect of intraarticular Neostigmine, tramadol, tenoxicam and Bupivacaine on postoperative pain. Ambulatory Surg. 2002; 10(1): 29-32.

9. Datta R and Madhusudanan TP. Pain relief following Arthroscopy - a comparative study of Intra-articular Bupivacaine, Morphine and Neostigmine. Med J Armed Forces India. 2004 Apr; 60(2): 123-127.

10. Alagol A, Calpur OU, Usar PS, Turan N, Pamukcu Z. Intra-articular analgesia after arthroscopic knee surgery: comparison of Neostigmine, clonidine, tenoxicam, Morphine and Bupivacaine. Knee Surgery, Sports Traumatology, Arthroscopy. 2005; 13(8): 658-663.

11. Yasin B, Kazi WA. Comparison of intra-articular pethidine and Neostigmine for postoperative analgesia in patients undergoing knee arthroscopy. Pakistan Armed Forces Med J. 2006; 56(3).

12. Lee DH. Intra-articular Neostigmine and Bupivacaine for Pain Relief after Knee Arthroscopy. Korean J Anesthesiol. 2000 Aug;39(2):212-217.

13. Nole R, Munson N, Fulkerson J. Bupivacaine and saline effects on the articular cartilage. Arthroscopy $1985 ; 1: 123-7$

14. Fulkerson J, Winters T. Articular response to arthroscopic surgery. A review of current knowledge. Arthroscopy 1986; 2:189-98.

15. Lauretti GR, de Oliveira R, Perez MV, Paccola CAJ. Postoperative analgesia by intra-articular and epidural Neostigmine following knee surgery. Anaesthesia 2000; 12(6): 444-448.

16. Rao SK and Rao PS. Comparison of Intra-Articular Analgesics for Analgesia After Arthroscopic Knee Surgery. Med J Malaysia 2005; 60(5): 560-562.

17. Kirdemir P, Marşan A \&Kirdemir V. Comparing analgesic effect of intraarticular Neostigmine, tramadol and tenoxicam with placebo. The Pain Clinic 2006; 18(3): 231-236.

18. Mitra S, Kaushal H, Gupta RK. Evaluation of analgesic efficacy of intraarticular Bupivacaine, Bupivacaine plus fentanyl, and Bupivacaine plus tramadol after arthroscopic knee surgery. Arthroscopy. 2011 Dec;27(12):1637-43.

19. Ozdemir N, Kaya FN, Gurbet A, Yilmazlar A, Demirag B and Mandiraci OB. Comparison of Intra-articular Bupivacaine and LevoBupivacaine with Morphine and Epinephrine for Knee Arthroscopy Eurasian J Med. 2013 Jun; 45(2): 77-82.

20. Xie D-x, Zeng C, Wang Y-1, Li Y-s, Wei J, Li H, et al. A Single-Dose Intra-Articular Morphine plus Bupivacaine versus Morphine Alone following Knee Arthroscopy: A Systematic Review and Meta-Analysis. PLoS ONE 2015; 10(10): e0140512

21. Sun QB, Liu SD, Meng QJ, Qu HZ and Zhang Z. Single administration of intra-articular Bupivacaine in arthroscopic knee surgery: a systematic review and meta-analysis. BMC Musculoskeletal Disorders 2015; 16:21

22. Nahravani M, Tekyehttp://abjs.mums.ac.ir/article_7857.html - au1 SMM, Alipour M, Makhmalbaf H, Aghaee MA. Analgesia Following Arthroscopy - a Comparison of Intra-articular Bupivacaine and/or Midazolam and or Fentanyl. Ar Bone \& Jt Surg. 2017; 5(1): 28-31.

Copyright: (C) the author(s), 2020. It is an open-access article distributed under the terms of the Creative Commons Attribution License (CC BY 4.0), which permits authors to retain ownership of the copyright for their content, and allow anyone to download, reuse, reprint, modify, distribute and/or copy the content as long as the original authors and source are cited.

How to cite this article: Singh P, Yadav SK, Kumar S, Tripathi M, Malviya D. Comparision of Intra-Articular Bupivacaine and Neostigmine with Bupivacaine and Fentanyl for Post-Operative Analgesia in Arthroscopic Knee Surgeries. Acad. Anesthesiol. Int. 2020;5(1):109-113.

DOI: dx.doi.org/10.21276/aan.2020.5.1.22

Source of Support: Nil, Conflict of Interest: None declared. 